\title{
Educación y reproducción social de las élites habaneras (1776-1804)
}

\author{
Álvaro ChAPARro SAINZ \\ Université de Lyon II \\ a.chaparrosainz@gmail.com
}

Recepción: 2 de marzo de 2009 / Revisión: 1 de junio de 2010

Aceptación: 15 de julio 2010 / Publicación: diciembre de 2010

\begin{abstract}
RESUMEN
Este trabajo pretende acercarse al conocimiento de la reproducción de las élites gobernantes de la Monarquía hispánica a finales del siglo XVIII, partiendo de las élites habaneras para descubrir un marco más amplio. Creemos que lo concreto nos lleva a lo general y que, por extensión, este ejemplo contribuye a plantear una Historia transatlántica de la Monarquía hispánica, sin fracturas. Como puede apreciarse en la investigación, las prácticas sociales para desplegar las estrategias familiares de reproducción social fueron las mismas en la metrópoli y en América. El Real Seminario de Vergara se conforma como un gran escenario en el que analizar las actitudes sociales de las familias de la élite habanera que buscaron perpetuarse en las estructuras de poder político. Las estrategias educativas llevadas a cabo por estas parentelas en un marco atlántico confirman el peso de la trayectoria individual, así como el porqué de la inversión familiar en este cometido. Las élites habaneras son, en nuestra opinión, un ejemplo paradigmático, no sólo dentro del cuerpo "americano" de los alumnos del Real Seminario de Vergara, sino también del conjunto de seminaristas que en este centro se formaron.
\end{abstract}

Palabras clave: Educación, élites, Monarquía, siglo XVIII, reproducción social, estrategias familiares, Real Seminario de Vergara.

\section{Education and Social Reproduction in Havana's Elites (1776-1804)}

\begin{abstract}
This article aims at analyzing the reproduction of the ruling elites of the Hispanic Monarchy at the end of the 18th century. The study of Havana's elites leads to a broader framework. In the conviction that the specific takes us to the general, this example contributes to the shaping of a transatlantic history of the Hispanic Monarchy, without fissures. The essay posits that the social practices that presided family strategies were the same ones in the metropolis and in America. Vergara's Royal Seminar allows us to analyze the social attitudes of the families belonging to Havana's elite, that sought to perpetuate themselves in the political structures. When seen from an Atlantic perspective, the educational strategies preferred by these families confirm the relevance of the individual path and justify their investment. Havana's elites are a paradigmatic example, not only within the "American" circle of pupils coming to Vergara's Royal Seminar, but also in relation to the entire group of seminarians who were educated in this institution.
\end{abstract}

Keywords: Education, Elites, Monarchy, 18th Century, Social Reproduction, Family Strategies, Vergara's Royal Seminar.

SUMARIO: 1. Introducción. 2. La élite habanera: trayectorias, carreras y estrategias familiares. 2.1. Espacios societarios: las sociedades económicas y las familias habaneras. 3. Las familias habaneras: una reproducción social a escala de imperio. 3.1 Las políticas educativas de las élites habaneras. 4. Conclusiones. 5. Referencias bibliográficas. 


\section{INTRODUCCIÓN}

De los 542 alumnos que entre 1776 y 1804 estudiaron en el Real Seminario Patriótico de Vergara ${ }^{1}, 112$ procedieron de América, lo que representa al 25\% del total. Esta cuantificación es, por sí misma, reveladora de un fenómeno particular y con una base explicativa que supera marcos establecidos tanto geográfica, como social, política y culturalmente ${ }^{2}$.

En este trabajo, al igual que en investigaciones anteriores, partimos de la extrañeza ${ }^{3}: ~ ¿$ no resulta insólito que en pocos años un destacado número de familias americanas decidiesen enviar a sus hijos a un centro educativo situado al otro lado del océano Atlántico?; ¿qué claves explicativas nos pueden ayudar a entender que cientos de jóvenes invirtiesen cuanto tenían en recibir educación en Vergara?

La investigación parte del estudio social de las familias que tomaron la decisión de enviar a sus descendientes al mencionado centro educativo. El Real Seminario de Vergara se postuló como una vía de éxito hacia las carreras de servicio al monarca para cientos de jóvenes ${ }^{4}$. Con todo, ¿cómo conocieron estas familias americanas las posibilidades que otorgaba Vergara? Los vínculos familiares, a escala de Imperio, entre las familias afincadas en América y sus parientes, en muchas ocasiones situados en las provincias vascas o territorios metropolitanos, podrían explicar este hecho.

Metodológicamente, la investigación se apoya en el seguimiento individual de los actores sociales, analizando sus trayectorias y sus experiencias, con el fin de obtener una visión de conjunto que permita describir modelos de actuación. Igualmente, aplicando el método de red social y el análisis del comportamiento familiar se busca comprender las actuaciones sociales de una parte de las élites americanas, en este caso, la élite habanera de finales del siglo XVIII ${ }^{5}$. Denominamos élite a los individuos que destacaban por ocupar cargos cardinales, principalmente en la administración y el ejército. Consideramos élites habaneras a un conjunto de familias que respondieron a este perfil tras protagonizar un proceso de ascenso social y colocarse en las altas esferas del poder político, económico y cultural de la ciudad cubana.

Las familias habaneras que optaron por Vergara para educar a sus hijos fueron un total de 22, lo que se tradujo en la llegada de 31 seminaristas, 30 de ellos durante el periodo comprendido entre 1783 y 1788 . Estas cifras indican la existencia de una

${ }^{1}$ A partir de este momento, al referirnos al Real Seminario Patriótico de Vergara lo haremos, indistintamente, a través de las siguientes denominaciones: Seminario de Vergara, Real Seminario de Vergara, Seminario etc. Pese a todo, siempre nos estaremos refiriendo a la misma institución.

${ }^{2}$ Según la ordenación política del territorio en el siglo XVIII, los lugares de origen de los más de cien seminaristas que cruzaron el Atlántico para llegar a Vergara, se clasificarían del siguiente modo: Capitanía General de Cuba (34), Virreinato de Nueva España (25), Virreinato del Perú (16), Virreinato del Río de la Plata (15), Virreinato de Nueva Granada (14), Capitanía General de Guatemala (3), Capitanía General de Chile (1), ubicación desconocida (4). La fuente utilizada para realizar las cuantificaciones ha sido: MARTínEZ RUIZ, 1972.

3 Imízcoz BeunZa - Chaparro SAInz, 2009, pp. 993-1028.

4 Véase Chaparro SAINZ, 2010a.

${ }^{5}$ Metodológicamente, partimos de las ideas expuestas en los trabajos de IMízCOz BEUNZA, 2004 y 2009. 
concreta política familiar dirigida desde La Habana, situada en esta cuestión por detrás de Vizcaya, Guipúzcoa, Navarra y Madrid; no obstante, dada la lejanía con respecto a Vergara, el caso habanero fue, sin duda, el más significativo. En nuestra opinión, la clave residió en la actividad de un grupo familiar y en las estrategias que establecieron las familias para sus descendientes. Es esta particularidad la que nos lleva a analizar la vinculación existente entre las parentelas habaneras y el Real Seminario Patriótico de Vergara y, como desenlace, atender a las estrategias de reproducción social derivadas de tal relación. El estudio del comportamiento social de la élite habanera en el seno del Real Seminario de Vergara se justifica como consecuencia de las particulares características de esta institución, auténtica plataforma hacia las estructuras de gobierno de la Monarquía para quienes en él estudiaron.

El perfil que presenta el conjunto de familias americanas fue, en general, el de comerciantes, terratenientes y funcionarios públicos ${ }^{6}$ insertos en dinámicas sociales ascendentes. Muchos de ellos eran oriundos de las provincias vascas o Navarra, por lo que el envío de parientes a Vergara significaría, a nuestro entender, un retorno de la familia a su lugar de origen donde, en ocasiones, permanecía algún familiar.

El Seminario de Vergara fue una institución educativa creada por los mismos individuos que, unos años antes, habían fundado la Real Sociedad Bascongada de los Amigos del País (RSBAP). En el seno de esta Sociedad destacaba, asimismo, el porcentaje de socios que tenían el mismo lugar de procedencia: América. Como a continuación se demostrará, el motivo por el que las familias de los seminaristas enviaron a sus parientes a estudiar a Vergara no fue otro que el de posibilitarles una carrera, siempre bajo la premisa de que Vergara fue un trampolín a través del que poder llevar a cabo sus propósitos. De acuerdo con las cifras aportadas por Torales Pacheco, "de los 515 amigos de la RSBAP localizados, 198 (38,5\%) tuvieron parte activa en las instituciones del Estado"7, destacado porcentaje de servidores del Rey que complementa al que hemos conseguido identificar para el conjunto de los socios de la Bascongada ${ }^{8}$, de los padres de los seminaristas ${ }^{9}$ o de los socios de otras Sociedades Económicas del momento ${ }^{10}$.

En conclusión, este trabajo pretende acercarse a la relación que se estableció entre las familias de la élite habanera y el Real Seminario Patriótico de Vergara, para entender mejor algunas claves de su reproducción social. Defendemos la hipótesis siguiente: las familias habaneras desplegaron las mismas estrategias observadas en grupos familiares peninsulares que habían protagonizado un ascenso social a lo largo del siglo XVIII y, que se habían servido del Seminario para posibilitar la reproducción de la parentela ${ }^{11}$.

\footnotetext{
6 Torales Pacheco, 2001, p. 127.

7 Ibídem, p. 243.

8 Imízcoz Beunza - Chaparro SaInZ, 2009.

9 Chaparro Sainz, 2009a.

10 Imízcoz Beunza - Chaparro Sainz, 2009.

11 Chaparro Sainz, $2010 \mathrm{~b}$.
} 


\section{LA ÉLITE HABANERA: TRAYECTORIAS, CARRERAS Y ESTRATEGIAS FAMILIARES}

El estudio del caso concreto de la ciudad de La Habana, por delante de otros espacios geográficos americanos, se explica al observar cómo en torno al 30\% de los alumnos del Seminario procedentes de América lo hicieron desde una misma ciudad. Sin duda se trata de un caso paradigmático. Más, si cabe, cuando la llegada de la inmensa mayoría de esos jóvenes se produjo entre 1783 y 1788, un intervalo de tiempo muy reducido.

La invasión inglesa de 1763 y la posterior recuperación española de la isla provocaron cambios en la sociedad habanera. Bajo el control político y económico de unas pocas familias, La Habana disfrutó de unos años de esplendor como consecuencia de las medidas económicas que favorecieron a una parte concreta de la sociedad, especialmente, a los productores azucareros. En la sociedad habanera del siglo XVIII destacaba la presencia de una oligarquía urbana "móvil", propietaria de ingenios de azúcar, junto a individuos cuya riqueza procedía de la actividad comercial ${ }^{12}$, así como funcionarios, autoridades, magistrados y otros personajes - oficiales del ejército y la marina por ejemplo- llegados de España por designación real o por compra de cargos.

A lo largo de varias generaciones, estas familias se hicieron con el control tanto de los órganos de poder local, como de la actividad eclesiástica, judicial, militar y marinera de La Habana ${ }^{13}$. En términos generales, protagonizaron un proceso social específico que se podría resumir del siguiente modo:

[...] el padre, o el abuelo, fueron hombres que llegaron a Cuba como funcionarios administrativos y casi siempre en la alta jerarquía militar y naval. Ya en la colonia, se enriquecen mediante la apropiación de los recursos del Estado, devienen en terratenientes, entroncan por casamiento con otras de las familias antiguas e intervienen en activos azucareros ${ }^{14}$.

Las familias que encontramos vinculadas al Real Seminario de Vergara a finales del siglo XVIII son las mismas que Manuel Moreno Fraginals identifica, desde 1761, como dueños de ingenios que "en los próximos cincuenta años han de llenarse de títulos nobiliarios"15, en clara referencia a la última etapa de su ascenso social. Los apellidos que el autor menciona son los mismos que aparecen como protagonistas de este artículo, es decir: Herrera, Garro, Santa Cruz, Montalvo, Cárdenas, Peñalver, $\mathrm{O}^{\prime}$ Farrill, Armenteros y Arango ${ }^{16}$. Familias que, insistimos, vivieron un proceso social ascendente y que desembocaron en el Seminario de Vergara dotando de educación a sus hijos.

12 Para más información en relación a las cuestiones económicas relativas a los ingenios azucareros ver, especialmente los siguientes trabajos: KNIGHT, 1977; TORNERO TINAJERO, 1986 y 1991; GARCÍA RODRÍGUEZ, 1998 y 1999.

13 Moreno Fraginals, 1995, p. 172.

14 Ibidem, p. 165.

15 Moreno Fraginals, 1964, p. 4.

16 Ibidem, p. 4. 
Este proceso histórico se sustentaba sobre estrategias sociales, pensadas y ejecutadas, que, de manera regular y continuada, llevaron a la conformación de "una elite criolla que [...] vivió un proceso de militarización, acumulación de riqueza y ennoblecimiento que le abrió las puertas de la Corte"17. Una realidad social que implicó la conformación final de "una red intrincada de familias" que, inicialmente, "había ido ocupando la tierra, criado ganado, producido tabaco en sus molinos y reunido un pequeño capital"18 y, que desembocó en el proceso social descrito. Como señalamos, la presencia de estas familias en la sociedad habanera no era una cuestión nueva, venía de atrás, $\mathrm{y}$, con el paso de las generaciones, llevó a la conformación de estrechos vínculos familiares que tuvieron su afianzamiento en los entronques matrimoniales.

[...] constituyen una sola familia [...] estableciendo cuidadosamente los vínculos entre sí, calculando económicamente cada unión para que la fortuna acumulada no se disperse y los cargos oficiales hereditarios queden siempre en el núcleo inicial ${ }^{19}$.

La trayectoria social de estos personajes, miembros de las familias que se estaban enriqueciendo a través de la producción de azúcar, les llevó, con el tiempo, a "adquirir acciones de la Real Compañía de Comercio lo que aceleró el estímulo inversionista en esta rama" 20 . Entre los que tomaron este camino encontramos a: Gonzalo de Herrera y Berrío, Bartolomé de Ambulodi y Arriola, Juan de Herrera, Juan Núñez de Castilla, Francisco Chacón o los hermanos Peñalver Angulo ${ }^{21}$, miembros de las familias anteriormente citadas.

La evolución de las trayectorias de estas familias les condujo, tras invertir en la producción azucarera y adentrarse en las estructuras comerciales, a interesarse por otros ámbitos de actuación que les permitiesen afianzarse en las estructuras del poder político de la isla y del Imperio. Así, los cargos dentro de la política local estaban, en gran parte, dominados, generación tras generación, por las mismas familias. Dominique Goncalvès ha mostrado cómo, entre 1763 y 1838, el 69\% de los alcaldes ordinarios de La Habana habían tenido un pariente en el cargo con anterioridad ${ }^{22}$.

Al igual que ocurrió en la península con familias que ascendieron socialmente, estas parentelas optaron por incorporarse, paulatinamente, al ejército ${ }^{23}$, a sabiendas de que la puerta de la milicia posibilitaba el acceso a los órganos más elevados de control político. Esta situación provocó que, entre finales del siglo XVIII y principios del XIX, surgiese "una alta oficialidad criolla insertada en el ejército español y una importante red de alianzas familiares con la oficialidad española peninsular"24. Todo ello como consecuencia de una política familiar según la cual, con "las mujeres de las familias se procuraron establecer alianzas que asegurasen o facilitasen los

\footnotetext{
17 GonZÁLEZ-RIPOLL, 2001, p. 295.

18 GONZÁLEZ-RIPOLL, 1999, p. 125.

19 Moreno Fraginals, 1964, p. 4.

20 GoNZÁLEZ-RIPOLL, 1999, p. 126.

21 Ibidem, p. 126.

22 GonCALVÈs, 2008, p. 97.

23 Este tema ha sido especialmente trabajado por: KUETHE, 1986 y 2005.

24 Moreno Fraginals, 1995, p. 163.
} 
objetivos políticos y económicos de la clase" 25 . El "fuerte interés por introducirse en los cuadros de la milicia" 26 supuso, al mismo tiempo, que "sólo unos pocos accederán a la burocracia y aún menos seguirán carrera eclesiástica” 27 . En relación a este idilio con el ejército, el siguiente cuadro recoge algunos de los miembros de la élite habanera vinculados a Vergara, junto al empleo que ostentaron dentro del arco cronológico $1750-1800^{28}$.

\begin{tabular}{|c|c|c|}
\hline Año & Nombre & Cargo militar \\
\hline 1750 & Peñalver Calvo Puerta, Sebastián & Coronel de milicias de La Habana \\
\hline 1763 & Aróstegui Larrea, Martín & Capitán del regimiento de caballería voluntario de La Habana \\
\hline 1763 & Cárdenas Castellón, Nicolás & Capitán del regimiento de caballería de voluntarios de La Habana \\
\hline 1763 & Chacón Torres, Francisco & Teniente coronel del reg. de infantería de voluntarios de La Habana \\
\hline 1764 & O'Farrill Herrera, Gonzalo & Cadete en la compańía de nobles de La Habana \\
\hline 1780 & Arredondo Pelegrín, Nicolás & Mayor General del ejército expedicionario de Cuba \\
\hline 1781 & Zaldivar Murguía, José Manuel & Capitán del primer batallón del reg. de infantería de voluntarios de Cuba \\
\hline 1782 & Chacón Herrera, José María & Capitán del regimiento de infantería de voluntarios de La Habana \\
\hline 1783 & Beltrán Santa Cruz, Joaquín & Oficial de los reales voluntarios de infantería de La Habana \\
\hline 1783 & Calvo Puerta, Sebastián & Teniente coronel del regimiento de infantería de Cuba \\
\hline 1783 & Veitia Castro, Antonio José & Coronel del regimiento de infantería de voluntarios de La Habana \\
\hline 1787 & Montalvo Ambulodi, Ignacio & Coronel del regimiento de caballería de voluntarios de La Habana \\
\hline 1787 & Peñalver Cárdenas, Ignacio & Teniente coronel del regimiento de infantería fijo de La Habana \\
\hline 1791 & Armona Murga, Matías & Coronel general de la Intendencia del ejército de La Habana \\
\hline 1792 & Calvo Puerta O'Farrill, Francisco & Coronel del regimiento De caballería de voluntarios de Cuba \\
\hline 1794 & Montalvo O'Farrill, José Joaquín & Capitán del regimiento de caballería de voluntarios de La Habana \\
\hline 1795 & Montalvo Ambulodi, Francisco & Teniente coronel del regimiento de infantería de La Habana \\
\hline
\end{tabular}

La obtención de un cargo en el ejército implicaba, para los miembros de la élite habanera, subir un peldaño más en la escala social. La ostentación de estos puestos se produjo en ocasiones a través de la compra de empleos, como ha demostrado Francisco Andújar Castillo. Las élites habaneras invirtieron parte de sus beneficios en la adquisición de oficialías militares como apuesta por el devenir de sus trayectorias, así

25 Ibídem, p. 163.

26 Amores Carredano, 2000, p. 253.

27 Ibidem, p. 253.

${ }^{28}$ La fuente utilizada para la realización del cuadro ha sido la base de datos FichOz. Bajo la dirección de Jean Pierre Dedieu, a quien agradezco su consulta, la base de datos está destinada, especialmente, al personal administrativo y militar de la Monarquía hispánica en la Edad Moderna. A día de hoy, en su interior se recogen las trayectorias de más de sesenta y cinco mil individuos. 
[...] dentro del grupo de compradores de un origen claramente burgués destacan aquellos cuyas familias acumularon capitales en América, bien a través de negocios bien por medio del ejercicio de empleos relacionados con la Administración ${ }^{29}$.

De este modo, confirmamos que una de las características que definían al grupo de familias de la élite habanera era que se encontraba inserto dentro de redes sociales en las que se gestionaban las ventas de cargos. Es el caso de los apellidos Peñalver, O'Farril, Montalvo, Ambulodi, Zayas, Colmenares o Chacón a quienes sus lazos profesionales, familiares o intelectuales, les llevaron a entablar relaciones con personajes vinculados con esta práctica, como serían los casos de Luis de las Casas o Alejandro de O'Reilly. Otro ejemplo podría ser el de la familia Peñalver. Según nos informa Andújar Castillo, la presencia de Diego Peñalver Calvo como Tesorero oficial de las Cajas Reales de La Habana "le permitió acumular la fortuna suficiente como para comprarle a su hijo Ignacio Peñalver una compañía en el regimiento del Príncipe el 22 de marzo de 1766"30. Como señala el mismo autor, "pocos espacios escapaban a una estrategia familiar perfectamente diseñada" 31 . Mientras Diego Peñalver Calvo se ocupaba en las finanzas reales, su hijo Ignacio lo hacía en el ejército, otros dos hijos en cargos de gobierno en La Habana y un cuarto hijo seguía la carrera eclesiástica en el cargo de Vicario General en el obispado de La Habana.

Otro ejemplo es Gonzalo O'Farrill. Su padre, Juan José O'Farrill Arriola "había abandonado su carrera en la marina para dedicarse a los negocios relacionados con el azúcar y con el ganado"32, convirtiéndose en un rico comerciante. Gracias a ese enriquecimiento, acumuló capital que invirtió en la compra de una plaza de Cadete en la Compañía de Nobles de La Habana y, en 1771, tras regresar de sus estudios en Sorèze -Francia-, de una compañía en el regimiento de la Princesa ${ }^{33}$. La familia O'Farrill se encontraba entroncada vía matrimonio con la familia Montalvo, la cual también protagonizó casos de compra de cargos militares. De este modo, se sabe que Francisco y Pedro Montalvo Ambulodi se hicieron con una compañía y una tenencia en el año $17733^{34}$.

El ascenso social tendría su fin con la obtención de un título nobiliario que pusiese fin a todo el proceso. Como señala Dominique Gonçalvès, "quelques familles havanaises [...] rêvaient de titres de Castille qui assureraient définitivement leur prééminence sociale et permettraient de nouvelles ambitions"35. En este sentido, Juan Bosco Amores señala cómo "hacia finales de siglo no había prácticamente ningún título habanero que no estuviere emparentado en primer o segundo grado con casi todos los demás". Las veinte familias que este autor indica como ostentadoras del poder a lo largo del gobierno de Ezpeleta (1785-1790) poseían titulación nobiliaria, poniendo así el colofón a su trayectoria social.

\footnotetext{
29 AndúJar CAstillo, p. 210.

30 Ibídem, p. 289.

31 Ibidem, p. 289.

32 Ibidem, p. 266.

33 Ibidem, p. 266.

34 Ibidem, p. 352.

35 GONCALVĖs, 2008, p. 156.
} 
No en vano, como ya hemos indicado anteriormente, las familias habaneras relacionadas con el Seminario de Vergara a raíz del envío de sus descendientes, podían tener más elementos comunes que la carrera y el desarrollo social. A todo lo dicho hasta aquí hay que añadir que, en muchas ocasiones, estas mismas parentelas compartieron experiencias culturales y asociativas que generalmente se transformaron en experiencias políticas y de poder.

\subsection{Espacios societarios: las Sociedades Económicas y las familias habaneras}

El control del poder, tanto económico como social de La Habana, se encontraba vinculado a una "veintena de grandes apellidos" 36 . Eran familias que compartían las mismas experiencias y actuaciones, lo cual compensaba que, en ocasiones, no estuviesen unidas por lazos de parentesco y sí a través de otros vínculos, por ejemplo, societarios. En esta línea, es posible vincular las familias ostentadoras del poder político habanero con la instauración de las Sociedades Económicas en los territorios americanos como consecuencia, principalmente, de sus medios económicos y de su acceso a la educación ${ }^{37}$. Las Sociedades Económicas se convirtieron, así, en "centros de acción política" donde se podía lograr la "inserción entre las élites"38.

El 25 de marzo de 1788 se reunió por primera vez la Sociedad Económica de Santiago de Cuba. De los 70 miembros reunidos, 26 eran militares (37\%), 17 clérigos seculares (24\%), 7 administradores, y otros 7 eran regidores. También se contabilizó a un profesor de cirugía. Por último, de 12 de ellos nada se sabe ${ }^{39}$. En consecuencia, más del $50 \%$ de los miembros de la Sociedad pertenecían a las más altas esferas del poder.

La Sociedad Económica de Amigos del País de San Cristóbal de La Habana nombró el 27 de abril de 1791 una diputación compuesta por: Luis Peñalver Cárdenas, Juan Manuel O'Farrill, Juan Francisco José Basabe e Ignacio Montalvo Ambulodi. Los cuatro pertenecían al grupo familiar vinculado al Real Seminario Patriótico de Vergara. Aún así, no debe sorprender que estuviesen emparentadas, ya que, como se ha mostrado, otras Sociedades Económicas fueron fundadas respondiendo a este mismo guión ${ }^{40}$.

Siguiendo las pistas familiares y sociales de estos cuatro individuos, cabe señalar cómo Ignacio Montalvo Ambulodi, de destacada carrera militar, en 1793 se le encomendó realizar un viaje para estudiar los métodos más avanzados en el refinamiento del azúcar ${ }^{41}$.

Luís Peñalver Cárdenas realizó estudios de teología en la Universidad San Jerónimo de La Habana, para doctorarse posteriormente en teología y cánones.

\footnotetext{
36 Amores Carredano, 2000, p. 60.

37 Ibidem, p. 261.

38 FRANCO RUBIO, 2005, p. 72.

39 Amores Carredano, 2000, pp. 265-266.

40 Aguinagalde Olaizola, 1988, pp. 397-444.

41 Gil Novales, 1991, p. 43.
} 
Director y fundador de la Sociedad Económica de La Habana en 1790, fue nombrado obispo de La Florida y de Luisiana en 1794, llegando a ser Arzobispo de Guatemala entre 1801-180642. Miembro de una familia de alcaldes y regidores de $\mathrm{La}$ Habana, su hermano Ignacio Peñalver Cárdenas ${ }^{43}$, teniente coronel del regimiento de infantería, llegó a tesorero del ejército de la misma ciudad. Por el contrario, su hermano Gabriel Peñalver Cárdenas, además de ocupar cargos en la política local, se casó con María Loreto Montalvo Ambulodi, hermana de Ignacio, conde de Casa Montalvo. En cuanto a Juan Manuel O'Farrill, es probable que fuera hermano de María Josefa O'Farrill Herrera, esposa de Ignacio Montalvo Ambulodi. Finalmente, Juan Francisco José Basabe pertenecería a la parentela de los Basabe que, afincados en La Habana, eran originarios de las provincias vascas ${ }^{44}$.

Hemos contabilizado 78 socios de la Real Sociedad Bascongada de los Amigos del País que residieron en La Habana. Conocemos la procedencia geográfica de 50: eran peninsulares 40, mientras que 10 socios aparecen como residentes en América. Destaca sobre manera cómo 30 de los 40 peninsulares eran de origen vasco-navarro. Entre los americanos sobresalen los intelectuales y los miembros de familias poderosas que reclamaban medidas para la liberación económica. Con respecto a los personajes situados en Cuba que formaban parte de la Bascongada, Ronald Escobedo y Juan Bosco Amores apuntan que

[...] los hombres que participan en el proyecto ilustrado pertenecen a los grupos preparados: alto clero, una parte de la nobleza y los patricios (formado este último por administradores de la Hacienda, juristas, militares de carrera, nuevos nobles, algunos intelectuales y técnicos) ${ }^{45}$.

Los perfiles de carrera de los socios contabilizados coinciden con el que, más concretamente, estamos viendo entre las élites habaneras que enviaron a sus hijos a Vergara. De los 78 socios, 21 se dedicaban al comercio, entendiendo dentro de este sector, por ejemplo, la producción azucarera. Un total de 25 socios ocupaban diferentes oficios en el gobierno y la administración de la isla, como eran los puestos en la Real Factoría de Tabacos, el Consulado, la Tesorería de la Administración General, etc; ocho individuos ostentaban cargos en el ejército, mientras que el resto se dividían entre la política local, la Sociedad Económica de La Habana o la carrera eclesiástica. Finalmente desconocemos el perfil de nueve sujetos.

Tras observar el desarrollo social de las principales familias habaneras vinculadas al Seminario de Vergara, en el siguiente apartado nos adentraremos en el comportamiento de este grupo. Su contextualización nos ha permitido identificar ante qué familias estamos, lo que nos permitirá centrarnos en ellas y analizar sus actuaciones, principalmente educativas, de cara a perpetuarse socialmente.

\footnotetext{
42 Base de datos Fichoz. Referencia: 026431. Magdaleno - Peña - Bordonau - PlazA, 1954, p. 265.

43 Base de datos Fichoz. Referencia: 022787. KuEthe, 1988, p. 126.

44 Base de datos Fichoz. Referencias: 026436, 022774 y 054474.

45 Escobedo Mansilla - Amores Carredano, 1992, p. 226.
} 


\section{LAS FAMILIAS HABANERAS: UNA REPRODUCCIÓN SOCIAL A ESCALA DE IMPERIO}

Creemos que lo ocurrido en La Habana debe entenderse a partir de los vínculos familiares y geográficos que muchas de las familias que enviaron a sus hijos a Vergara tenían con las provincias vascas. Un notable número de estas personas poseían apellidos vascos y sabemos que, en ocasiones, apenas llevaban dos generaciones en La Habana. Por lo tanto, casi con seguridad seguirían manteniendo estrechos lazos con la comunidad de origen.

Analizando las familias que enviaron a sus hijos a Vergara, observamos cómo éstas estaban emparentadas entre sí46. El amplio entramado de lazos familiares dibujaba una tela de araña que se establecía por encima de cualquier demarcación política y conformaba una red social "a escala de Imperio" 47.

Las familias Peñalver, Cárdenas, Calvo Puerta, Echevarria, Arredondo, Beltrán Santa Cruz, Montalvo, O'Farril, etc. conformaban un mapa familiar en el que estaban representados varios de los seminaristas habaneros. En ocasiones, y pese a que no ha sido confirmado, estas familias estaban vinculadas con otras parentelas también representadas en el Seminario: es el caso de la unión entre las familias Beltrán Santa Cruz y Risel.

El desarrollo social de este grupo familiar nos lleva a establecer que los vínculos familiares no se limitaban a individuos que se encontraban en La Habana, sino que también abarcaban otros territorios, incluida la península. Así, observamos que la familia Peñalver estaba emparentada con la familia Gastón de Iriarte -originaria de Navarra-, que por estas fechas tenía varios miembros en Cartagena de Indias. Se constatan, en definitiva, vínculos familiares que se situaban por encima del entramado político, económico y cultural de La Habana, de América y de todo el Imperio.

A través de los matrimonios se han podido reconstruir amplios entramados familiares en los que sus miembros respondían a un perfil social idéntico. Esto nos induce a pensar que no estamos hablando de grupos de familias individualizadas o inconexas, puesto que conforme vamos ampliando el marco de análisis el tejido se extiende y las dimensiones son realmente muy difíciles de manejar.

Otro grupo lo forman las familias Gardoqui - O'Reilly - Las Casas - Justiz. Será esta última la que vinculará a este grupo familiar con el de los Gastón de Iriarte Peñalver - Cárdenas - Calvo Puerta - Beltrán Santa Cruz, a través de los lazos matrimoniales con la familia Calvo Puerta O'Farril. La familia Justiz es de origen guipuzcoano, ya que el padre del seminarista Ignacio Justiz, nacido en La Habana donde llegó a ser Sargento Mayor, descendía de Juan Justiz Echeverria, abuelo del alumno de Vergara que había nacido en Aduna, Guipúzcoa. Sin duda alguna, el matrimonio fue la unión más habitual y sólida dentro de estas familias de cara a entender y dibujar su composición y sus relaciones.

Las familias habaneras no fueron las únicas que respondieron a esta estructura social. Este perfil de las familias que se encontraban gobernando la Monarquía tam-

46 Ver el trabajo genealógico de GonCALVÈs, 2008.

47 Imízcoz Beuna - Guerrero EleCAlde, 2001, p. 175. 
bién se ha observado desde el otro lado del océano. Establecer lazos entre ambos márgenes fue muy habitual. En esta ocasión, sólo hemos querido destacar esta dinámica en el caso de las parentelas habaneras, que, sin embargo, responde a un comportamiento más amplio y general ${ }^{48}$. Así, los puentes establecidos por estas familias a escala de Imperio fueron muy abundantes. Además de los ejemplos arriba expuestos, existen otras relaciones establecidas, preferentemente, a través de vínculos matrimoniales que constituyeron relaciones sólidas. Es el caso del vínculo entre el apellido Enrile y el apellido Ezpeleta. María Paz Enrile Alcedo, hermana del seminarista habanero Francisco Enrile Alcedo, casó con José Manuel Ezpeleta Galdiano, primer conde Ezpeleta Veire. Nacido en Pamplona, con apenas catorce años ingresó como cadete en el regimiento de infantería de la Corona (1756), para continuar una trayectoria que lo llevó a ser Teniente General (1792) ${ }^{49}$. La carrera de José Manuel Ezpeleta Galdiano en el ejército estuvo marcada por la intervención favorable de Alejandro de O'Reilly. Junto a él sirvió en Cuba en 1763. En ese momento, José Manuel Ezpeleta fue Ayudante Mayor de La Habana, colaborando con O'Reilly en la instrucción de las milicias de ciudad ${ }^{50}$.

La política familiar de los Enrile llevó a María Paz Enrile Alcedo a casar a sus hijos con miembros de parentelas muy afines a los círculos en los que se movían. María Concepción Ezpeleta Enrile casó con Pedro Girón Casas Moctezuma Aragorri, perteneciente a la parentela que anteriormente hemos desarrollado de los GardoquiCasas-O'Reilly-Aragorri-Justiz. Por su parte, José María Ezpeleta Enrile se casó con María Amalia Aguirre Zuazo Acedo, nacida en Vitoria en 1801 y nieta de José María Aguirre Ortés de Velasco, director de la Real Sociedad Bascongada de los Amigos del País tras la muerte del conde de Peñaflorida en 1785 y uno de los egos de la red que tejieron los ilustrados vascos entre la propia Sociedad y la corte ${ }^{51}$.

No obstante, el análisis de las relaciones exclusivamente a través de esquemas genealógicos nos impide ver toda la realidad. Si bien son útiles para mostrar el desarrollo social y familiar de la parentela y apreciar los puntos de unión de diferentes familias, esta opción no muestra ni el conjunto de la red, ni las posibles relaciones. El análisis de la documentación y, en especial, el vaciado de la correspondencia epistolar nos pueden mostrar otros vínculos que no tienen por qué ser familiares y que a la larga pueden resultar igualmente efectivos. En este sentido, hemos observado cómo estas relaciones se podían sustentar en elementos como la amistad o la vecindad. Respecto de esta última idea, hemos tenido ocasión de analizar el comportamiento de Manuel José de Torrontegui a la hora de interceder para que los hijos de sus "vecinos" pudiesen incorporarse a las aulas del Seminario de Vergara.

48 En este sentido, entre los muchos existentes, se podrían consultar: CAULA MAMUT, 1998-1999 y 2008; ZÚÑIGA, 2002; BERTRAND, 2003.

49 Base de datos Fichoz. Referencia: 009652. Contaduría general de la distribución, mercedes y franquicias (1792-1792), 16-IV-1792, Archivo General de Simancas (en adelante AGS), Dirección General del Tesoro (en adelante DGT), Inventario 2, leg. 76.

50 Base de datos Fichoz. Referencia: 009652. Secretaría del Despacho de Guerra, Hojas de servicio de infantería (1712-1805), III-1763, AGS, Guerra Moderna (en adelante GM), leg. 2631.

51 Chaparro SAINZ, 2009b, pp. 193-208. 
Representantes de la élite habanera decidieron enviar a sus hijos a centros educativos peninsulares, como es el caso del Real Seminario de Vergara. El motivo de esta práctica se debía a que "el déficit de instrucción elemental en la isla era enorme", problema que "no empezó a resolverse hasta los últimos años del siglo, cuando se hizo cargo del asunto la Sociedad Económica de La Habana"52.

Las familias habaneras reprodujeron la actuación de miembros de su mismo grupo familiar que se encontraban instalados cerca de Vergara y de la Sociedad Bascongada y enviaron a una notable representación de sus descendientes a estudiar al Seminario. Como ya conocemos, fueron 31 los seminaristas de Vergara que procedieron de La Habana. Es digno de destacar cómo 20 de ellos llegaron al Seminario junto a algún hermano. Sabemos que la llegada de alumnos a Vergara acompañados por parientes fue una actuación muy habitual entre los jóvenes. Sin embargo, para el caso de La Habana el ejemplo supera la media del Seminario. Se observa, por tanto, cómo esta práctica familiar resultaba más habitual cuanto más grande fuera la distancia entre la ciudad de origen y Vergara.

Al mismo tiempo que los seminaristas solían llegar allí acompañados de algún hermano o pariente, existió la figura de los criados, tutores o responsables que secundaban a los seminaristas a su llegada a la península. Sin embargo, el papel de los responsables no se limitó, únicamente, a hacer las veces de cuidador, ya que se ocupaba de otras tareas, como la de ser el intermediario entre el Seminario y sus gestores y la familia del seminarista. Según hemos observado en la documentación, éstos contaban con la ayuda de alguna persona que les esperaba en tierra tras el viaje en barco. Estas personas, que desconocemos si eran contratadas por las familias o dispuestas por la propia Bascongada, se encargaban de recoger a los jóvenes y dirigirlos a Vergara. Esta actuación se observaba en la figura de Nicolás Peñalver Cárdenas, que envió a tres de sus hijos a Vergara y puso en manos de José Ramón Zubiria la salud y bienestar de sus descendientes. Al mismo tiempo, el propio Nicolás Peñalver, a través de la figura de José Ramón Zubiria, se postuló como informante de la situación de otros hijos de parientes que igualmente se encontraban en el Seminario. Es el caso de los dos seminaristas Echeverria Peñalver, primos de los Peñalver Cárdenas, que estuvieron, como informa Nicolás Peñalver al Seminario, al cargo de José Ramón Zubiria.

Los seminaristas optaron, mayoritariamente, por los puertos del norte de la península para llegar a Vergara. San Sebastián y Bilbao fueron los embarcaderos más habituales. En otras ocasiones, optaron por puertos como Santander o Cádiz, elegido este último, por ejemplo, por los tres seminaristas Torrontegui Fernández de Landa. Es muy probable que al ser Manuel José Torrontegui comerciante tuviese en Cádiz alguna persona a la que encomendarle el cuidado de sus hijos a su arribada a suelo andaluz. Esta persona bien podría haber sido Bartolomé Alsazua, comerciante en Cádiz y quien permaneció en Jalapa (México), entre 1777 y $1786^{53}$, territorio en el que sabemos mantuvo contactos comerciales Manuel José Torrontegui.

Analizando las trayectorias de los seminaristas una vez abandonaron el Seminario, observamos cómo la salida preferente por la que optaron fue el ejército.

\footnotetext{
52 Amores Carredano, 2000, p. 260.

53 Martínez Ruiz, 1985, p. 24.
} 
Una práctica que también hemos observado como la más habitual dentro del conjunto de los alumnos que pasaron por el Seminario de Vergara ${ }^{54}$.

\begin{tabular}{|c|c|}
\hline Nombre & Cargo \\
\hline Basabe Cárdenas, Luis Anastasio & Alférez de fragata de la Real Armada \\
\hline Basabe Cárdenas, Rafael José de & Alférez de fragata de la Real Armada \\
\hline Cobarruvias Montalvo, Juan Nepomuceno & Capitán de milicias de infantería \\
\hline Echevarria Peñalver, Manuel José. & Presbítero, Caballero supernumerario \\
\hline \multicolumn{2}{|l|}{ Echevarria Peñalver, Martín Francisco } \\
\hline Echegoyen Arostegui, Juan Bautista & Sargento mayor de dragones de Milicias disciplinadas de Guatemala. \\
\hline Enrile Alcedo, Francisco María & Capitán de fragata de la Real Armada \\
\hline González Benítez, Ignacio & Comerciante \\
\hline Justis Urrutia, Ignacio María & Alférez de navío de la Real Armada \\
\hline \multicolumn{2}{|l|}{ Lanz Márquez, Juan Bautista } \\
\hline \multicolumn{2}{|l|}{ Lanz Márquez, Manuel } \\
\hline Lasa Ribas, Sebastián José de & Comerciante y hacendado \\
\hline \multicolumn{2}{|l|}{ Liendo Gutiérrez, José } \\
\hline \multicolumn{2}{|l|}{ Loisaga Benevento, Ramón José } \\
\hline Loynaz Lizundia, Francisco de & Regidor de La Habana \\
\hline Loynaz Lizundia, Ignacio & Sargento de infantería \\
\hline Madan Gutiérrez, José Joaquín & Comerciante de esclavos negros desde Matanzas \\
\hline Matienzo Ugarte, Domingo & Cadete regimiento de infantería de La Habana \\
\hline Matienzo Ugarte, José Domingo & Teniente de fragata de la Real Armada \\
\hline Patrón Yraurgui, Juan José & Subteniente \\
\hline Peñalver Cárdenas, Diego Nicolás & Comerciante de esclavos negros desde Matanzas \\
\hline Peñalver Cárdenas, Francisco José & Regidor de La Habana \\
\hline Peñalver Cárdenas, Juan Francisco & Teniente del cuerpo de caballería Ligera de Luzón \\
\hline \multicolumn{2}{|l|}{ Pitaluga Casas, Juan Guillermo } \\
\hline Rizel Beltrán Santa Cruz, Pedro Valiente & Capitán del Segundo batallón de artillería \\
\hline Rizel Beltrán Santa Cruz, Vicente María & Subteniente de artillería \\
\hline Seidel Tabares, Antonio José & Teniente de Guardia Jalonas \\
\hline Seidel Tabares, José María & $\begin{array}{l}\text { Teniente Coronel de infantería Agregado al Estado Mayor de } \\
\text { La Habana }\end{array}$ \\
\hline Torrontegui Fdez. Landa, Félix Antonio & Teniente de navío de la Real Armada \\
\hline Torrontegui Fdez. Landa, Francisco José & Alférez de fragata de la Real Armada \\
\hline Torrontegui Fdez. Landa, Rufino José & Teniente de navío de la Real Armada \\
\hline
\end{tabular}

54 Chaparro SAINZ, 2009c, pp. 55-82. 
¿Por qué el ejército como salida masiva? Como ya hemos observado, Manuel Moreno Fraginals destacó la evolución de las familias habaneras hacia la milicia. El interés por el ejército no es gratuito, ya que esta dinámica se convirtió en un nuevo escalón dentro de la carrera por situarse en la esfera de poder que suponía el servicio al monarca. Aunque la composición de los grupos familiares de élite habanera se caracterizaba por su heterogeneidad, el ejército se convirtió en la opción preponderante. Así, una generación más tarde da la sensación de que existía una única vía para los jóvenes deseosos de hacer carrera. De hecho, tenemos la impresión de que aquellos que no optaron por el ejército lo hicieron en virtud de los trabajos y compromisos que competían a la familia, perpetuándose en el lugar de origen, enfrenando la administración de los bienes de la casa y ocupando los cargos políticos que sus parientes habían ejercido durante las últimas décadas.

En el cuadro de las carreras por las que optaron los seminaristas habaneros se observa -aunque la identificación no se encuentre al cien por cien- el claro perfil dentro de los descendientes de la élite de finales del siglo XVIII. El Ejército y la Marina se muestran como las mejores opciones de cara a hacer carrera. De los 31 seminaristas habaneros, 18 ocuparon cargos militares, es decir, un 58\% del total. De los militares, ocho hicieron carrera en la Armada, mientras que la mayoría, 10 exactamente, ocuparon cargos en el ejército. En cuanto a las carreras de los seminaristas que no han sido identificadas, cabe establecer como hipótesis que algunos alumnos de Vergara pudieron asistir al Seminario como meros "acompañantes", teniendo que regresar a casa tras haber recibido educación. De este modo se les habría imposibilitado tener una carrera. En estos casos, la educación recibida les serviría para manejar los recursos familiares con mejores conocimientos. En la medida en que esta hipótesis sea corroborada, los hombres que se encontrasen dentro de esta trayectoria quedarían omitidos por parte de la documentación.

\subsection{Las políticas educativas de las elites habaneras}

La política educativa de las familias habaneras hacia sus hijos estaba determinada con antelación. Los padres conocían los caminos por los que debían transitar sus hijos de cara a optar a una carrera. Por ello, actuaban en consecuencia, decidiendo las materias que debían estudiar, en qué cuestiones debían hacer especial hincapié y cuándo debían abandonar el Seminario.

Las familias habaneras, alejadas de la metrópoli, participaron de las mismas estrategias familiares que otras muchas familias insertas en idénticos procesos sociales, lo que nos lleva a pensar en las dinámicas de grupo y actuaciones en clave de red social. El comportamiento de los grupos familiares instalados en la Corte se repetía en los diferentes miembros de la parentela, beneficiándose todos de las oportunidades y recursos. Las élites habaneras, tras un largo proceso de enriquecimiento e inversión para su ascenso social, se encontraron ante la necesidad y la obligación de reproducirse socialmente. Para ello, no dudaron en redoblar los esfuerzos de cara a formar a sus descendientes ante la posibilidad de promocionarse.

Una de las principales características que determinaba las actuaciones de estas familias fue la distancia que les separaba de sus hijos y parientes. La corresponden- 
cia epistolar nos muestra cómo gracias a los intercambios regulares que se produjeron mediante el intercambio de misivas entre los responsables, la distancia parecía no ser tan amplia. Así se expresaba Juan José Justiz cuando desde La Habana escribió que "aunque tan distantes, tenemos bastantes noticias de lo de por allá" 55 . Es precisamente a esa distancia a la que hace mención un padre afectado por la separación de su hijo:

[...] tenga la bondad de encargar particularmente la instrucción y aprovechamiento de unos hijos que separamos de nuestro abrigo en tan tierna edad a tanta distancia sin otro objeto que el de que se hagan hombres útiles, y por esto capaces de adquirir la estimación de sus jefes o sujetos que traten ${ }^{56}$.

La falta de noticias es, normalmente, la gran preocupación de los padres, especialmente cuando carecen de información acerca de las notas que sus hijos obtenían en el Seminario. Era precisamente mediante esos informes que los padres conseguían tener noticias de los avances o retrocesos de sus descendientes. Juan José Justiz escribía preocupado el 9 de marzo de 1790 a José Antonio Olaeta para decirle que se sentía extrañado por no haber recibido las notas de "los exámenes generales que se hacen por cuatrimestres", ya que

[...] nos sirve aquí de consuelo, y para gobierno, pues por ellos se ve el estado y aprovechamiento que logran los hijos, por lo que suplico a vm me tenga presente para remitirme el último estado que se formó para dicho mi hijo ${ }^{57}$.

Cinco meses después, Juan José Justiz volvía a ponerse en contacto con el Seminario. El 10 de agosto de 1790, en carta dirigida a Manuel Gaytán Ayala, conde del Sacro Romano Imperio, informaba que a su hijo Ignacio María, "colegial actual en ese Seminario", al estar "próximo a concluir su gramática" le convenía "entrar a estudiar matemáticas"58. Esta misma noticia hizo llegar Juan José a su hijo, con quien se escribía regularmente. Le informa de la situación de la familia y de lo que establece con los responsables del Seminario en relación a su educación. Así, le hacía saber que había escrito al conde (del Sacro Romano Imperio) "para que entres en matemáticas, si estas capaz para ello"59.

La intromisión de los padres en la educación de sus hijos alcanzó niveles tan altos que su mediación obligaba a los maestros a variar las asignaturas que debían impartir en función de las preferencias de aquellos. De este modo, Juan Bautista Lanz, administrador habanero que había enviado a dos hijos a estudiar al Seminario

55 Carta de Juan José Justiz a José Antonio de Olaeta, La Habana, 2-II-1788, Bergarako Udal Artxiboa (en adelante BUA) Fondo Real Seminario (en adelante FRS), caja 7007-02.

56 Carta de Juan José Justiz a José Antonio de Olaeta, La Habana, 2-II-1788, BUA, FRS, caja, 7007-02.

57 Carta de Juan José Justiz a José Antonio Olaeta, La Habana, 9-II-1790, BUA, FRS, caja 7007-02.

58 Carta de Juan José Justiz al Conde del Sacro Imperio Romano, La Habana, 10-VIII-1790, BUA, FRS, caja, 7007-02.

${ }^{59}$ Carta de Juan José de Justiz a Ignacio de Justiz, La Habana, 10-VIII-1790, BUA, FRS, caja 7007-02. 
escribió una carta a José Antonio Olaeta en la que le suplicaba que "de ninguna manera dejen el ejercicio de escribir diariamente, pues concluida la latinidad, pensaré, y avisaré lo demás que deban emprender". El 11 de noviembre de 1791, Juan Bautista de Lanz escribió a Manuel Gaytán de Ayala para solicitarle "que si es posible a esos Juan Bautista y Manuel que se hallan en ese colegio se les dedique a la música de violín y baile, en aquellos ratos en que no estén dedicados al estudio"60. Por otro lado, Vicente Risel se dirigió a José Antonio de Olaeta en diciembre de 1788 para decirle que "me parece lo más conveniente que desde luego se dedique al estudio de las matemáticas, lenguas francesas e inglesa", a lo que agregó "se incline en baile y esgrima y a que se perfeccione en escribir" 61 . Estas materias debían ser, en opinión del padre, las más adecuadas para la formación de un militar, ya que fue ésta la vía por la que optaron los dos seminaristas tras abandonar Vergara.

Al igual que la situación de los estudios, las familias se cuestionaban diariamente por la salud de los seminaristas. Es por ello que las cartas en las que se da noticia de su estado fueron muy bien recibidas por los padres. Es lo que se observaba en la carta escrita por Juan José Patrón, en la que señalaba cómo

[...] la noticia que me conduce y la que me acredita la que da esta suya mi amado hijo relativa a la salud cumplida que quedaba disfrutando, es la principal, que deseaba, y deseo, y la que merece en mi la primicia en todos mis gustos y satisfacciones ${ }^{62}$.

El principal motivo que movía a estas familias a la hora de procurar todos los medios que favoreciesen la educación de sus hijos no era otro que posibilitarles una salida profesional. Volviendo al ejemplo de Manuel José de Torrontegui, este padre deseaba que su hijo se dirigiese a la Marina. Del mismo modo lo debía ver el presidente del Seminario de Vergara cuando se dirigió al mencionado Manuel José haciendo referencia a ese posible destino. A este comentario respondió Torrontegui en una carta en la que decía acerca de unos de sus hijos:

[...] le contempla vm en disposición de presentarse con lucimiento al examen que quiera hacérsele sufrir en la Marina, u otro cualesquiera cuerpo al que se le destine"63.

Pese a que desconocemos la carrera por la que optó Francisco de Torrontegui Fernández Landa, podríamos afirmar, casi con total seguridad que, de cara a ingresar en la Marina, habría sido muy valiosa la entrada que allí tenía Francisco Xavier Matienzo, "Ministro principal de Marina" como lo presenta Manuel José de Torrontegui, a quien el propio Manuel José ayudó para que sus hijos entrasen a estudiar al Seminario. Es decir, podemos observar un beneficio mutuo gracias a las relaciones personales y a las posibilidades de acción de cada uno de los interesados.

60 Carta de Juan Bautista Lanz al Conde del Sacro Imperio Romano, La Habana, 11-XI-1791, BUA, FRS, caja 7007-02.

61 Carta de Vicente Risel a José Antonio de Olaeta, La Habana, 00-XII-1788, BUA, FRS, caja 7007-02.

62 Carta de Juan José Patrón a José Antonio Olaeta, La Habana, 4-II-1788, BUA, FRS, caja 7007-02.

63 Carta de Manuel José de Torrontegui a José Antonio de Olaeta, La Habana, 21-XI-1788, BUA, FRS, caja 7007-02. 
Sin embargo, no siempre la educación de los seminaristas estuvo dirigida por los padres exclusivamente. De hecho, ante su ausencia o por otras razones, en ocasiones eran las propias madres hicieron frente a la educación de sus hijos. Una de estas mujeres que siguió con atención los avances de sus hijos en Vergara fue María Luisa Cárdenas, madre de tres seminaristas, que, el 1 de febrero de 1788, escribió una carta desde La Habana a José Antonio de Olaeta. La misiva decía que

[...] en la apreciada de vm del 19 de noviembre del año pasado veo la buena salud y aplicación en que continúan mis tres amados hijos y que ratificando v. su oferta en los esfuerzos contribuirá a la perfección de sus carreras para que pueda ver yo logrado el fin que me movió a la separación de estos tres tiernos pedazos de mi corazón ${ }^{64}$.

En ocasiones, las madres intercedían en la correspondencia para dar noticia al Seminario de acontecimientos luctuosos como el fallecimiento del padre de los estudiantes. Fue el caso de María Micaela de Ugarte, quien escribió a José Antonio Olaeta desde La Habana para comunicarle el fallecimiento de su marido como consecuencia de una pulmonía y solicitarle que comunicase la noticia a sus dos hijos. En la carta, señalaba:

[...] ruego a vm tenga a bien hacer uso de su prudencia haciéndosela saber y consolándolos en mi nombre, con la dulzura y cariño que exige su edad y amargo del suceso" 65 .

Ante este hecho, María Micaela debió volcarse en la educación de sus hijos, tal y como se observa en una carta posterior. En ella, escrita desde La Habana a Joaquín de Lezama el 14 de agosto de 1790, la viuda indicaba:

[...] me parece muy bien que el mayor piense de la manera que vm me indica para su aprovechamiento, porque es cierto que en las vacaciones regularmente pierden los muchachos mucha parte de lo que han aprendido. Me parece decir vm que respecto a que mis hijos no han de ser eclesiásticos sería conveniente que desde luego se les aplicase a las matemáticas, dejando de gastar así el tiempo en la gramática latina. Sírvase vm hacerlo presente a quien corresponde, a fin de que den principio a aquellos en el próximo cuatrimestre" 66 .

Pese a encontrarse sin un marido que orientase la trayectoria de sus hijos, María Micaela de Ugarte se enfrentó a la vida y dirigió de manera excelente la educación de sus seminaristas. De este modo, en 1789, mientras que sus hijos estudiaban en el Real Seminario de Vergara, solicitó les fuesen abonados "sus haberes como si estuvieran incorporados a sus banderas" 67 por ser cadetes del Regimiento de Infantería de Cuba.

${ }^{64}$ Carta de María Luisa de Cárdenas a José Antonio de Olaeta, La Habana, 1-II-1788, BUA, FRS, caja 7007-02.

65 Carta de María Micaela de Ugarte a José Antonio de Olaeta, La Habana, 1-XII-1788, BUA, FRS, caja 7007-02.

66 Carta de María Micaela de Ugarte a Joaquín de Lezama, La Habana, 14-VIII-de 1790, BUA, FRS, caja 7007-02.

67 Carta de María Micaela de Ugarte a Joaquín de Lezama, La Habana, 14-VIII-de 1790, BUA, FRS, caja 7007-02. 
Otros miembros de la familia intervinieron igualmente en las trayectorias educativas de los seminaristas habaneros que se encontraban en Vergara. Precisamente, como consecuencia de la distancia que separaba a los miembros de la familia, los padres delegaron sus funciones en parientes cercanos. Esto es lo que ocurrió con Andrés de Loyzaga, quien en diciembre de 1788 escribía desde La Habana a José Antonio Olaeta, para orientarle sobre las pautas que debía tomar en la educación de su hijo Ramón, así como para informarle que "con esta fecha tengo escrito a mi hermano D. Silvestre vecino de Cádiz para que se informe y si fuere necesario contribuya con lo que fuese" 68 . La cercanía de Vergara con otras localidades en las que se encontraban parientes, amigos o personajes afines a la familia del seminarista, favorecía el establecimiento de estrechas redes de relaciones entre los diferentes personajes como consecuencia de la educación de los descendientes de la familia.

Ésta situación se repite en el caso de Juan José Basabe, quien en calidad de tío y tutor de dos seminaristas escribió a José Antonio de Olaeta con el objeto de señalarle cómo:

D. Luís y D. Rafael de Basabe sobrinos carnales míos, hijos de D. Luís de Basabe mi hermano viudo se hallan desde abril del corriente de seminaristas en ese Patriótico Bascongado, al que estoy admitido como socio, ellos están a mi dirección muchos años hace, su padre me ha otorgado escript. En que me constituye tutor y curador de ellos ampliamente atendiendo a sus atrasos de fortuna para que yo procure su educación y carrera, con la recaudamiento de sus cortos haberes. La constitución decadente del referido mi hermano le obliga a estar retirado en el campo, y los portes de cartas le son gravosos; en esta virtud y en el concepto de que por mi dirección y abrigo se ven en esa carrera prevengo a Vm se entienda conmigo en lo sucesivo, sin embargo que los chicos pueden escribir bajo de mi cubierta a su padre en todos los correos. En vista de las notas del primer examen quedo impuesto de la poca aplicación de los chicos, ya les escribo sobre esto lo más conveniente estando persuadido que su esmero por una parte y por otra el velo con que se llevan adelante las primeras intenciones de esa Ilustre Fundación. Hará relucir en lo venidero sus talentos que me parece no están dotados en los más inferiores ${ }^{69}$.

Por último, el 11 de octubre de 1790, Juan José Basabe se dirigió nuevamente a José Antonio Olaeta para comentarle que

[...] de las notas últimas del mes de enero que me incluye $\mathrm{Vm}$ de mis dos sobrinos D. Luís y D. Rafael de Basabe, deduzco hacen pocos progresos, siendo el mayor el menos aplicado. Como en las anteriores reitero a $\mathrm{Vm}$ los esfuerzos dobles a fin de que ponga de su parte cuanto le parezca necesario a efecto de que no se les haga infructuoso el tiempo"70.

68 Carta de Andrés Loyzaga a José Antonio de Olaeta, La Habana, 3 diciembre de 1788, BUA, FRS, caja 7007-02.

69 Carta de Juan José de Basabe a José Antonio de Olaeta, La Habana, 20-XII-1788, BUA, FRS, caja 7007-02.

70 Carta de Juan José de Basabe a José Antonio de Olaeta, La Habana, 11-X-1790, BUA, FRS, caja 7007-02. 


\section{CONCLUSIONES}

En definitiva, las familias habaneras que enviaron a estudiar a sus hijos a Vergara poseían una serie de características que las presentan como un interesante modelo de análisis para entender los comportamientos de las familias de las élites que, a lo largo del siglo XVIII, protagonizaron unos determinados procesos de ascenso social y colocación en los espacios de control político de la Monarquía. Pese a encontrarse alejadas de la metrópoli, estas familias participaron de las mismas estrategias que otras muchas parentelas de la península insertadas en procesos sociales idénticos, lo cual nos obliga a pensar en las dinámicas de grupo y actuaciones en clave de red social. La particularidad que aporta el caso de la élite habanera reside en la posibilidad de analizar un comportamiento familiar sin obstáculos geográficos o políticos y que entiende al conjunto de la Monarquía como escenario en el que actuar y llevar a cabo sus estrategias familiares. Es un ejemplo que sitúa al grupo familiar por encima de las estructuras políticas, económicas, sociales y culturales que dirigen y sustentan el gobierno. Su análisis supera los casos locales o regionales y posiciona al Imperio como tablero de juego.

Los comportamientos de estos grupos familiares instalados en la Corte se repitieron entre los diferentes miembros, y todos ellos se beneficiaron de las mismas oportunidades y recursos. Tras un largo proceso de enriquecimiento e inversión para su ascenso social, las élites habaneras se encontraron ante la necesidad y obligación de reproducirse en las posiciones en las que se venían situando. Para ello, no dudaron en invertir en la educación de sus hijos de cara a formarles ante la posibilidad de optar a una carrera. Por todo ello, el análisis de las familias habaneras resulta paradigmático y abre nuevas visiones sobre los comportamientos de la élite en torno a su reproducción social.

\section{REFERENCIAS BIBLIOGRÁFICAS}

Aguinagalde Olaizola, Borja de

1988 "La fundación de la Real Sociedad Bascongada de los Amigos del País, ¿un asunto de familia?". II Seminario de Historia de la Real Sociedad Bascongada de los Amigos del País. Donostia - San Sebastián. Real Sociedad Bascongada de los Amigos del País, pp. 397-444.

ÁlVAREZ CUARTERO, Izaskun

1992 "Las Sociedades Económicas de Amigos del País en Cuba (1787-1832): una aportación al pensamiento ilustrado". En NARANJO OROVIO - TALLO GUTIÉRREZ (eds.), pp. 35-44.

2000 Memorias de la Ilustración: las Sociedades Económicas de Amigos del País en Cuba (1783-1832). Madrid. Real Sociedad Bascongada de los Amigos del País.

Amores CARredano, Juan Bosco

2000 Cuba en la época de Ezpeleta. Pamplona. Ediciones Universidad de Navarra. 
ANDÚJAR CASTILLO, Francisco

2004 El Sonido del dinero. Monarquía, ejército y venalidad en la España del siglo XVIII. Marcial Pons. Madrid.

2008 Necesidad y venalidad: España e Indias 1704-1711. Madrid. Centro de Estudios Políticos y Constitucionales.

AstigarRaga, Jesús - LóPez Cordón, María Victoria - URKia, José María (coords.)

2009 Ilustración, ilustraciones. Vol. 2. San Sebastián. Real Sociedad Vascongada de Amigos del País.

BERTRAND, Michel

2003 "Entre Espagne et Amérique: un outil au service de l'etude des liens interpersonnels". En BEAUREPAIRE, Pierre-Yves - TAURISSON, Dominique (eds.). Les Ego-documents à l'heure de l'électronique. Nouvelles approches des espaces relationnels. Montpellier. Université Paul Valéry-Montpellier III, pp. 435-445.

Chaparro Sainz, Álvaro

2009a "Estudio prosopográfico del Real Seminario de Vergara: las políticas educativas de las familias ilustradas vascas". En Soria MesA, Enrique - Molina Recio, Raúl (eds.), Las élites en la época Moderna: la Monarquía Española, Vol. 2: Familia y redes sociales. Córdoba. Servicio de Publicaciones Universidad de Córdoba, pp. 109-119.

2009b "La fundación del Real Seminario de Vergara: las relaciones de los ilustrados vascos en la Corte". En AstigarRaga - LÓPEZ CORDÓN - URKIA (coords.), pp. 193-208.

2009c "Del pupitre a la espada: el Real Seminario de Vergara, cantera de militares“. Revista de Demografía Histórica. Barcelona. XXVII. 1. Segunda época, pp, 55-82.

2010 "Grupos familiares ilustrados en el siglo XVIII: redes, reproducción social y educación”. En IMÍzcoz BeunZA, José María - OLIVERI KORTA, Oihane (eds.). Economía doméstica y redes sociales. Madrid. Sílex, pp. 449-470.

Caula Mamut, Elsa

1998-99 "Redes sociales y poder político. La trayectoria social, económica y política de una familia vasca. Buenos Aires, 1750-1850". Anuario de Estudios Bolivarianos. Caracas. $\mathrm{n}^{\circ}$ 8-9, pp. 185-204.

2008 Tramas familiares y configuraciones mercantiles de origen vasco en el pasaje del orden político colonial al revolucionario. El Río de la Plata entre 1776 y 1820. Tesis doctoral inédita leída en la Universidad del País Vasco.

Escobedo Mansilla, Ronald - Amores Carredano, Juan Bosco

1992 "La Real Sociedad Bascongada de los Amigos del País en Cuba". En La Real Sociedad Bascongada y América. San Sebastián. Fundación BBV - Real Sociedad Bascongada de los Amigos del País, pp. 223-238. 
Franco RuBio, Gloria Ángeles

2005 "El ejercicio del poder en la España del siglo XVIII. Entre las prácticas culturales y las prácticas políticas”. Melanges de la Casa de Velázquez. Madrid. no 35-1, pp. 51-77.

GARCÍA RodRÍGUEZ, Mercedes

1998 "El crédito hipotecario a los ingenios habaneros (1700-1792)". En PiQueras ArenA, José Antonio (coord.). Diez nuevas miradas de historia de Cuba. Castellón de la Plana. Universitat Jaume I, pp. 41-66.

1999 "El privilegio de los ingenios en el mundo azucarero de Cuba (15981792)". Rábida. Huelva. no 18, pp. 91-104.

Gil Novales, Alberto

1991 Diccionario biográfico del Trienio Liberal. Madrid. Ediciones El Museo Universal.

GonZÁleZ-Ripoll, María Dolores

1994 "Voces de gobierno: los bandos del Capitán General Luis de las Casas, 17901796”. En Naranjo Orovio - Tallo GutiÉrRez (eds.), pp. 149-162.

1999 Cuba, la isla de los ensayos. Cultura y sociedad (1790-1815). Madrid. CSIC.

2001 "Vínculos y redes de poder entre Madrid y La Habana: Francisco Arango y Parreño". Revista de Indias. Madrid. vol. LXI. n 222, pp. 291-306.

GonCALVÈs, Dominique

2008 Le planteur et le roi. L'aristocratie havanaise et la couronne d'Espagne (1763-1838). Madrid. Casa de Velázquez.

ImízCoz BeunZA, José María

2004 "Actores, redes, procesos: reflexiones para una historia más global". Revista da Facultade de Letras. Historia. Oporto. III Série. vol. 5, pp. 115-140.

2009 "Las redes sociales de las élites". En Soria MeSA, Enrique - Bravo CARo, Juan Jesús - Delgado BARrado, José Miguel (eds.). Las élites en la época moderna: La Monarquía española. Nuevas perspectivas. Vol. 1. Córdoba. Servicio de Publicaciones de la Universidad de Córdoba, pp. 77-111.

Imízcoz Beunza, José María - Chaparro SAInz, Álvaro

2009, "Los orígenes sociales de los ilustrados vascos". En AstigarRAGA LÓPEZ CORDÓN - URKIA (coords.), pp. 993-1028.

Imízcoz BeunzA, José María - Guerrero EleCALDE, Rafael

2001 "A escala de Imperio. Familias, carreras y empresas de las elites vascas y navarras en la Monarquía borbónica”. En Imízcoz BeunzA, José María (dir.). Redes familiares y patronazgo. Aproximación al entramado social del País Vasco y Navarra en el Antiguo Régimen (siglos XV$X I X)$. Bilbao. Universidad del País Vasco, pp. 175-202

KNIGHT, Franklin W.

1977 "Origins of Wealth and the Sugar Revolution in Cuba, 1750-1850". Hispanic American Historical Review. Durham. n 57, pp. 231-253. 
KuETHE, Allan

1986 Cuba: 1735-1815, crown, military and society. Knoxville. University of Tenesse Press.

Kuethe, Allan - MARChenA, Juan (eds.)

2005 Soldados del Rey. El ejército borbónico en América colonial en vísperas de la Independencia. Castellón de la Plana. Universitat Jaume I.

LE RIVEREND BRUSONE, Julio

1992 La Habana, espacio y vida. Madrid. Fundación MAPFRE.

Magdaleno, Ricardo (dir.) - PeñA, José María de la - Bordonau, Miguel - PlazA, Ángel de la

1954 Catálogo XX del Archivo General de Simancas. Títulos de Indias. Valladolid. Patronato Nacional de Archivos. XV. p. 265.

MARRERO, Levi

1972 Cuba: Economía y Sociedad. 15 tomos. Madrid. Editorial San Juan.

MARTíNEZ RuIz, Julián

1972 Filiación de los seminaristas del Real Seminario Patriótico Bascongado y de nobles de Bergara. San Sebastián. Real Sociedad Bascongada de Amigos del País.

1985 Catálogo General de individuos de la Real Sociedad Bascongada de los Amigos del País (1765-1793). San Sebastián. Sociedad Guipuzcoana de Ediciones y Publicaciones.

Moreno Fraginals, Manuel

1964 El ingenio. El complejo económico social cubano del azúcar. La Habana. Comisión Nacional Cubana de la Unesco.

1995 Cuba/España España/Cuba. Historia Común. Barcelona. Editorial Grijalbo Mondadori.

NAranjo Orovio, Consuelo - TAllo Gutiérrez, Tomás (eds.)

1994 Cuba la perla de las Antillas. Actas de las I Jornadas sobre Cuba y su Historia. Madrid. Doce Calles - CSIC.

RuIZ RivERA, Julián - SANZ TAPIA, Ángel (coords.)

2007 La venta de cargos y el ejercicio del poder en Indias. León. Universidad de León.

SANTA CRUZ y Mallén, Francisco Xavier de

1940 Historia de familias cubanas. 9 volúmenes. La Habana. Editores Hércules.

SANZ TAPIA, Ángel

2009 ¿Corrupción o necesidad? La venta de cargos de Gobierno americanos bajo Carlos II (1674-1700). Madrid. CSIC.

ToRAles PaCheco, Cristina

2001 Ilustrados en la Nueva España. Los socios de la Real Sociedad Bascongada de Amigos del País. México. Universidad Iberoamericana - Real Sociedad Bascongada de los Amigos del País - Colegio de San Ignacio de Loyola. 
Tornero Tinajero, Pablo

1986 "Ingenios, planificación y esclavitud: una aproximación al estudio de los esclavos en los ingenios cubanos (1760-1821)". Anuario de Estudios Americanos. Sevilla. $\mathrm{n}^{\circ} 43$, pp. 35-68.

1991 "Producción y costes en los ingenios de Cuba: notas para una investigación". Arbor: ciencia, pensamiento y cultura. Madrid. $\mathrm{n}^{\circ}$ 547-548, pp. 139-160.

ZÚÑIGA, Jean Paul

2002 Espagnols d'Outre-Mer. Emigration, métissage et reproduction sociale à santiago de Chili au $17^{e}$ siècle. París. EHESS. 